
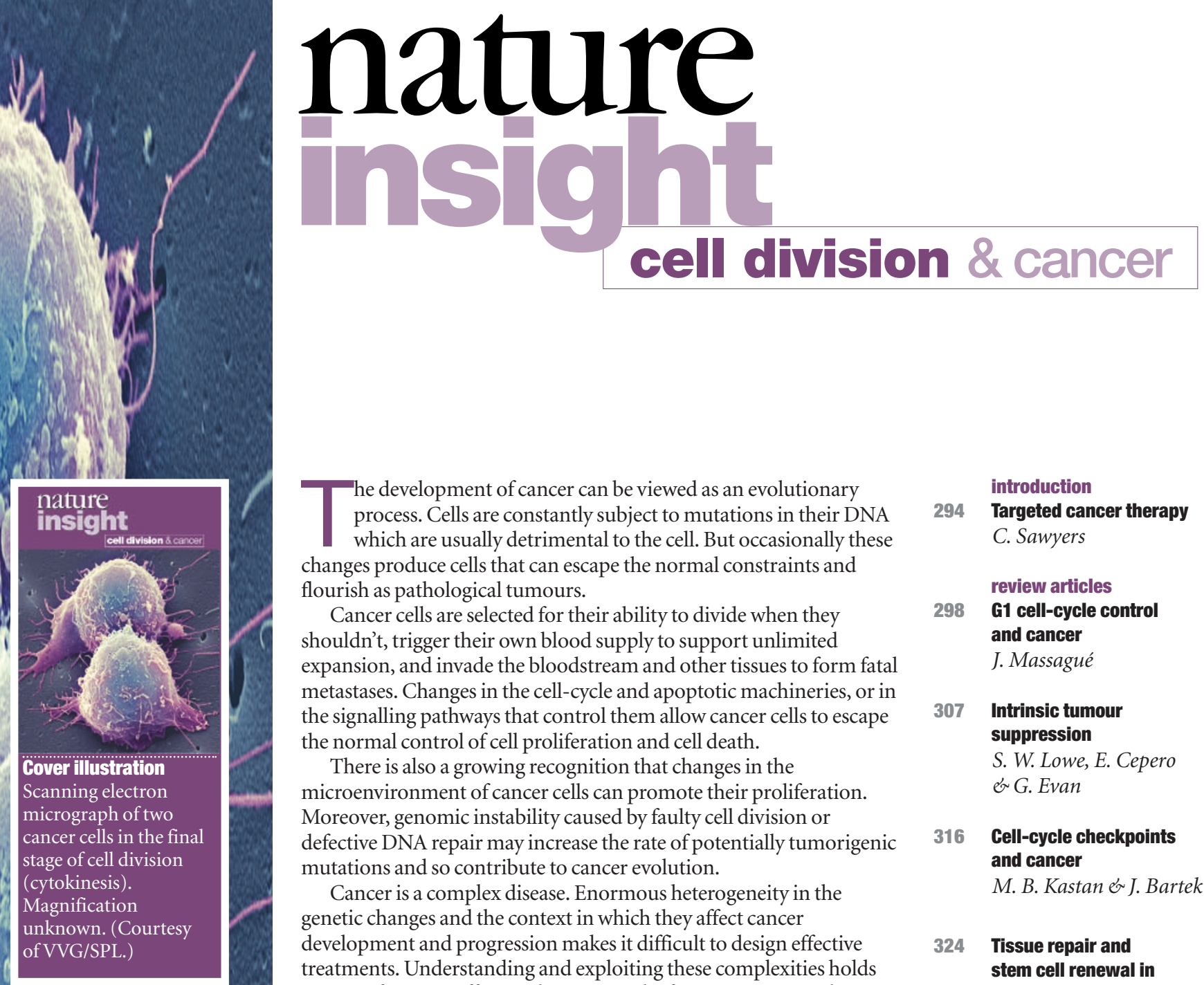

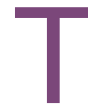
he development of cancer can be viewed as an evolutionary process. Cells are constantly subject to mutations in their DNA which are usually detrimental to the cell. But occasionally these changes produce cells that can escape the normal constraints and flourish as pathological tumours.

Cancer cells are selected for their ability to divide when they shouldn't, trigger their own blood supply to support unlimited expansion, and invade the bloodstream and other tissues to form fatal metastases. Changes in the cell-cycle and apoptotic machineries, or in the signalling pathways that control them allow cancer cells to escape the normal control of cell proliferation and cell death.

There is also a growing recognition that changes in the microenvironment of cancer cells can promote their proliferation. Moreover, genomic instability caused by faulty cell division or defective DNA repair may increase the rate of potentially tumorigenic mutations and so contribute to cancer evolution.

Cancer is a complex disease. Enormous heterogeneity in the genetic changes and the context in which they affect cancer development and progression makes it difficult to design effective treatments. Understanding and exploiting these complexities holds promise for more effective therapies in the future. Moreover, the notion that tumour maintenance critically depends on a small subset of cells with stem-cell-like behaviour may mean that a cancer cure ultimately has to target these cells.

Paradoxically, the altered cellular networks of molecular pathways that sustain cancer cell growth and make them resistant to certain therapies may offer new targets for therapy. Critical signalling junctions may exist that are more important for the survival of cancerous than normal cells.

We hope the articles in this Insight capture the excitement and promise of this rapidly advancing field. We are grateful to the authors for their contributions and to the reviewers for their valuable input.

We are pleased to acknowledge the financial support of AstraZeneca in producing this Insight. As always, Nature carries sole responsibility for the editorial content and peer review.

Barbara Marte Senior Editor
Editor, Nature: $\quad$ Philip Campbell Insight Publisher: Sarah Greaves Insight Editor: Lesley Anson Editorial Assistant: Timothy Gibbs Art Editor: Martin Harrison Diagrams:
Production Editor: Lucy Odling-Smee Layouts: Nadia Rooney introduction

ancer therapy

C. Sawyers

review articles

G1 cell-cycle control and cancer

J. Massagué

\section{Intrinsic tumour} suppression

S. W. Lowe, E. Cepero \& G. Evan

Cell-cycle checkpoints and cancer

M. B. Kastan \& J. Bartek

324 Tissue repair and stem cell renewal in carcinogenesis

P. A. Beachy,

S. S. Karhadkar \&

D. M. Berman

\section{Stromal fibroblasts in cancer initiation and progression}

N. A. Bhowmick,

E. G. Neilson \&

H. L. Moses

\section{progress}

338 Aneuploidy and cancer H. Rajagopalan \& C. Lengauer
Sponsorship: Claire Hines Production: Sue Gray Marketing: Claire Aspinall 